\title{
Skeletal modification in response to flow during growth in colonies of the sea whip, Junceella fragilis
}

\author{
Wan-Lan Chang ${ }^{\text {a }}$, Kai-Jung Chi ${ }^{\text {a,b }}$, Tung-Yung Fan ${ }^{c}$, Chang-Feng Dai ${ }^{\text {a,* }}$ \\ a Institute of Oceanography, National Taiwan University, Taipei, 106 Taiwan, R.O.C. \\ ${ }^{\mathrm{b}}$ Department of Physics, National Chung Hsing University, Taichung, 402 Taiwan, R.O.C. \\ ${ }^{c}$ National Museum of Marine Biology and Aquarium, Checheng, Pingtung, 944 Taiwan, R.O.C.
}

Received 7 July 2006; received in revised form 22 March 2007; accepted 23 March 2007

\begin{abstract}
Sessile marine organisms depend on water motion for important physiological functions yet face dislodgement or breakage caused by hydrodynamic forces. During growth, these organisms are subjected to increasing bending moments as height increases and they may modify their mechanical supports accordingly. Here we used the sea whip Junceella fragilis as a model species to examine how sessile organisms modify their skeletal supports to cope with hydrodynamic forces during growth. Eighty-one colonies of $J$. fragilis (height $5-156 \mathrm{~cm}$ ) were collected from two populations in southern Taiwan. Within-colony variations in skeletal elements, namely the axial skeleton and sclerites, as well as the coenenchyme and water content were investigated by measurements taken from the base, middle, and top of colonies. The typological distribution of sclerites within colonies was examined in another 31 colonies. The results showed that the relative weight of axial skeleton increases while that of sclerites decreases with colony height, which suggests that the colony switches from using sclerites to axial skeleton as the main support system during growth. The axial skeleton at the colony base thickens in such a way as to maintain or slightly decrease its bending stress. A greater density of sclerites, mostly double-heads, found at the colony base also adds to the resistance to bending. Moreover, colonies living in environments with greater flows seem to incorporate more skeletal materials. This study demonstrates how sessile marine organisms cope with increasing hydrodynamic forces during their life history by modifying the constitution and construction of their skeleton elements.
\end{abstract}

(C) 2007 Elsevier B.V. All rights reserved.

Keywords: Adaptations to flow; Allometry; Biomechanics; Gorgonian corals; Hydrodynamic forces; Sessile organisms; Skeletal modification

\section{Introduction}

Sessile marine organisms depend on water motion for important physiological functions (e.g. gas exchange, nutrition, and reproduction, etc.) yet face dislodgement or breakage caused by hydrodynamic

\footnotetext{
* Corresponding author. Tel./fax: +886 223916693.

E-mail address: corallab@ntu.edu.tw (C.-F. Dai).
}

forces (Jokiel, 1978; Shashar et al., 1996). Such selection pressure becomes even stronger for those living in shallow waters where the hydrodynamic force is greater (Koehl, 1984; Denny, 1988; Vogel, 1994). To understand how these organisms survive and interact with flow environments, it is essential to understand the mechanics of their skeletons (Koehl, 1984; Wainwright et al., 1976). Previous studies examined morphological/ mechanical adaptations of support systems at the species 
or population level (Muzik and Wainwright, 1977; Jeyasuria and Lewis, 1987; West et al., 1993; Denny, 1999; Denny and Gaylord, 2002; Kim et al., 2006); however, these adaptations during life history have rarely been studied (Koehl, 1999). In this study, we used the gorgonian coral Junceella fragilis as a model species to examine how sessile organisms modify their skeletal supports to cope with varied hydrodynamic forces during growth.

Gorgonian corals have two types of skeletal support: the axial skeleton and sclerites embedded within the coenenchyme, a common tissue mass connecting individual polyps. The axial skeleton is mainly composed of gorgonin in the form of collagen fibers in a proteinaceous matrix that is deposited in concentric layers around a central canal (Goldberg, 1976). Such material and structure are believed to provide tensile strength and elasticity (Wainwright et al., 1976; Lewis et al., 1992). Inclusion of calcium or magnesium carbonate into the axis further increases its stiffness (Esford and Lewis, 1990; Grillo et al., 1993). The stiffness (Young's modulus of elasticity) reported for gorgonian axial skeletons ranges from 0.6-9.0 $\mathrm{GN} \mathrm{m}^{-2}$ (Jeyasuria and Lewis, 1987; Boller et al., 2002). The other skeletal support system, calcitic sclerites embedded in the coenenchyme, may vary in shape, size, density, and spatial distribution. Although commonly considered a form of physical defense against predators (Harvell and Suchanek, 1987; Harvell et al., 1988; Harvell and Fenical, 1989; Van Alstyne and Paul, 1992; West, 1996, 1997, 1998), sclerites stiffen soft tissues, hence they may also provide mechanical support (Koehl, 1982; Lewis and Von Wallis, 1991). The stiffness of coenenchyme with sclerites in soft corals ranges from 2.7-5.5 $\mathrm{MN} \mathrm{m}^{-2}$ (Koehl, 1982), which is three orders of magnitude smaller than that of the gorgonian axial skeleton. Although the mechanical characteristics of both gorgonian axial skeleton and sclerites have been correlated with the flow environment (Grigg, 1972; Jeyasuria and Lewis, 1987; West et al., 1993; West, 1996), their relative importance has yet to be examined.

For gorgonian corals living in shallow water, drag $(D)$ is the dominant hydrodynamic force (Denny, 1999), and can be calculated as (Vogel, 2003):

$D=\frac{1}{2} C_{\mathrm{d}} \rho S v^{2}$,

where $C_{\mathrm{d}}$ is the drag coefficient (the value of which depends on the shape of the object and the flow regime), $\rho$ is the density of fluid, $S$ is the area of the object projected in the direction of flow, and $v$ is the flow velocity. Thus, for gorgonian corals with similar shape, the drag increases with their size and the ambient velocity. Most gorgonians are flexible and can deform or reorient, hence lowering the drag by reducing the projected area (Wainwright and Dillon, 1969; Grigg, 1972; Muzik and Wainwright, 1977; Lin and Dai, 1996; Lin and Dai, 1997). Some can even avoid the mainstream flow by bending the entire colony close to the reef surface (Muzik and Wainwright, 1977). The maximum stress, $\sigma_{\max }$ (tensile or compressive due to bending), on a bending gorgonian colony occurs at its base when the colony just begins to deform and can be calculated as (Denny, 1988):

$\sigma_{\max }=\frac{M d_{\mathrm{a}}}{2 I}$,

where $M$ is the bending moment, $d_{\mathrm{a}}$ is the diameter of the axial skeleton at the colony base, and $I$ is the second moment of area. As derived in the Appendix, the maximum bending moment can be calculated as:

$M=\frac{1}{4} C_{\mathrm{d}} \rho \cdot(h \cdot S) \cdot v^{2}$,

where $h$ is the colony height. Therefore, the maximum bending stress can further be related to the flow and the morphological characteristics of the colonies as:

$\sigma_{\max }=\frac{8 C_{\mathrm{d}} \rho}{\pi} \cdot\left(\frac{h^{2} d_{\mathrm{c}}}{d_{\mathrm{a}}^{3}}\right) \cdot v^{2}$.

That is, the maximum bending stress on the axial skeleton due to drag is a function of the velocity $(v)$, the colony height $(h)$, the mean diameter of the colony $\left(d_{\mathrm{c}}\right)$, and the axial diameter at the colony base $\left(d_{\mathrm{a}}\right)$. At a given flow velocity, the maximum stress on the axis increases


adding materials only lengthwise (modular growth), i.e. $d_{\mathrm{c}}, d_{\mathrm{a}} \propto h^{0}$, the maximum stress would increase with $h^{2}$. In contrast, if the colony grew by adding materials lengthwise and circumferentially at the same rate (isometric growth), i.e. $d_{\mathrm{c}}, d_{\mathrm{a}} \propto h^{1}$, the maximum stress would keep constant. Whether gorgonian corals grow in a way to prevent the stress from increasing is an interesting question. Here we used $J$. fragilis as a model system to address the question about skeletal adaptation in sessile marine organisms over the stages of colonial growth.

$J$. fragilis, a common sea whip in shallow IndoPacific coral reefs (Chen and Chang, 1991; Fabricius and Alderslade, 2001), is a non-branching gorgonian that can reach a height of over $1 \mathrm{~m}$ (Vermeire, 1994; Walker and Bull, 1983). Its simple geometry provides an opportunity to assess the relative importance of sclerites and the axial skeleton, as well as to calculate the 
hydrodynamic forces on the entire colony during growth. Colonies of $J$. fragilis in southern Taiwan grow in locations where strong currents or surges may occur (Chen and Chang, 1991). Daily maximum flow velocities near these locations range from $0.3-0.7 \mathrm{~m} \mathrm{~s}^{-1}$ during winter, and the wave forces are much greater during the typhoon season in summer (Lee et al., 1999). Growing at a maximum rate of $1.4 \mathrm{~cm}$ per week (Walker and Bull, 1983), a J. fragilis colony taller than $1 \mathrm{~m}$ suggests it has survived for at least 1-2 yr and must have encountered stronger wave forces in summer.

As the colony grows, it faces not only an increased drag (Eq. (1)), but also increasing bending moment and stress (Eqs. (3), (4)). Here, we examine the morphology and skeletal constituents of $J$. fragilis colonies across a range of sizes and from two locations with different flow environments. We hypothesized the following three points. (1) The gorgonin axial skeleton becomes the dominant mechanical support in taller colonies due to its greater stiffness than sclerites. (2) The diameter of the axial skeleton, especially at the colony base, is disproportionately greater in taller colonies in order to maintain a constant maximum stress across the size range. In particular, a constant stress in the axial skeleton of the same material property can be achieved by making the ratio $\frac{h^{2} d_{\mathrm{c}}}{d^{3}}$ independent of colony size (colony height h) (see Eq. (4)), i.e., $\frac{h^{2} d_{\mathrm{c}}}{d^{3}} \propto h^{0}$, or $\sqrt{\frac{d_{c}^{3}}{d_{\mathrm{c}}} \propto h}$. (3) The allometric patterns of skeletal characteristics should differ between two populations living in different flow environments.

\section{Materials and methods}

\subsection{Sample collection and study sites}

A total of 81 colonies of $J$. fragilis $(5-156 \mathrm{~cm}$ in height) were randomly collected from coral reefs at depths of $8-10 \mathrm{~m}$ at Leidashi $\left(21^{\circ} 55^{\prime} 53.5^{\prime \prime} \mathrm{N}, 120^{\circ} 44^{\prime} 41.1^{\prime \prime} \mathrm{E}\right.$; $n=62)$ and Xiashuijui $\left(22^{\circ} 02^{\prime} 12.3^{\prime \prime} \mathrm{N}, 120^{\circ} 41^{\prime} 28.3^{\prime \prime} \mathrm{E}\right.$; $n=19$ ) in southern Taiwan during August 2001 (Fig. 1). Hydrographic studies near the two sites showed that during winter the flow at Leidashi is omni-directional and is significantly stronger (maximum velocity is $0.7 \mathrm{~m} \mathrm{~s}^{-1}$ ) than that at Xiashuijui where the current is bi-directional (maximum velocity is $0.3 \mathrm{~m} \mathrm{~s}^{-1}$ ) (Lee et al., 1999; Lee, H.J., personal communication). Coral specimens were transported in seawater to the laboratory for morphometric measurements and content analyses.

\subsection{Morphometrics and skeletal contents}

Colony height was measured from the holdfast to the tip of the colony. The diameter of the colony $\left(d_{\mathrm{c}}\right)$ and the axial skeleton $\left(d_{\mathrm{a}}\right)$, after removing the coenenchyme, were measured at the top ( $1 \mathrm{~cm}$ below the tip), middle, and base ( $2 \mathrm{~cm}$ above the holdfast) of each colony. Hence the thickness of coenenchyme can be calculated as the difference between the diameter of the colony and that of the axial skeleton.

Four major components in a J. fragilis colony, namely the axial skeleton, sclerites, fleshy coenenchyme, and

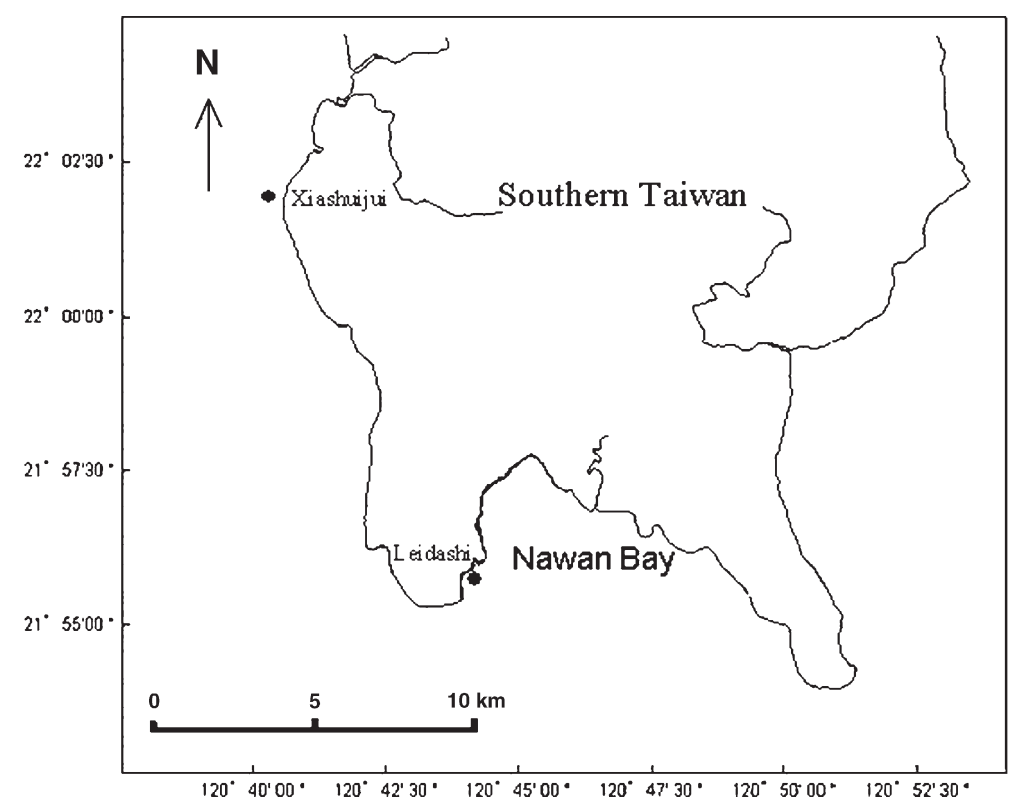

Fig. 1. Location of the two study sites in southern Taiwan: Leidashi and Xiashuijui. 
water content were measured. Firstly, the axial skeleton and coenenchyme of each colony were separated and their wet weights were measured separately. Subsequently, the coenenchyme was dried at $100{ }^{\circ} \mathrm{C}$ for $24 \mathrm{~h}$ and its dry weight was measured. Then, the dried coenenchyme was ashed at $500{ }^{\circ} \mathrm{C}$ for $3 \mathrm{~h}$ and the ash weight was measured, representing the weight of sclerites. Hence the water content of coenenchyme is the difference between its wet weight and dry weight; and the tissue weight is the difference between the dry weight and ash weight of coenenchyme.

\subsection{Sclerite weight and typological distribution}

Thirty-one $J$. fragilis colonies of $8-131 \mathrm{~cm}$ in height were collected from the same sites in August 2002 and February 2003. To examine how sclerites were distributed within a colony, samples of approximately $1 / 30$ of the total length were removed from the top, middle, and base of each colony. The content (water, tissue, and sclerites) of coenenchyme was analyzed by the same procedure described above. The weight fraction of sclerites was calculated as the sclerite weight divided by the dry weight of coenenchyme (Harvell and Suchanek, 1987).

To analyze the typological distribution of sclerites within a colony, three more coenenchyme samples were collected adjacent to where tissue was taken for the weight fraction analysis. After dissolving the organic matter of the coenenchyme using sodium hypochlorite, the sclerites from each sample were spread onto three slides for examination under a light microscope. Sclerites under nine haphazardly selected fields per slide were counted (West, 1998) and identified as three major types: double-head, club, and spindle (Chen and Chang, 1991) (Fig. 2). The relative frequency of each sclerite type was calculated and the length of the ten longest sclerites was measured using image analysis software (Image-Pro Plus, Media Cybernetics).

\subsection{Maximum bending moment and stress in the axial skeleton}

The maximum bending moment and stress in the axial skeleton at a flow of $1 \mathrm{~m} \mathrm{~s}^{-1}$ were calculated using Eqs. (3) and (4). The drag coefficient, $C_{\mathrm{d}}$, was assumed to be 1 for a cylinder over the approximate range of Reynolds numbers (between $10^{3}$ and $10^{5}$ ) encountered by corals on the reef, and the density of sea water, $\rho$, is $1030 \mathrm{~kg} \mathrm{~m}^{-3}$ (Vogel, 2003). Because $J$. fragilis colonies are tapered cylinders, its maximum projected area, $S$,
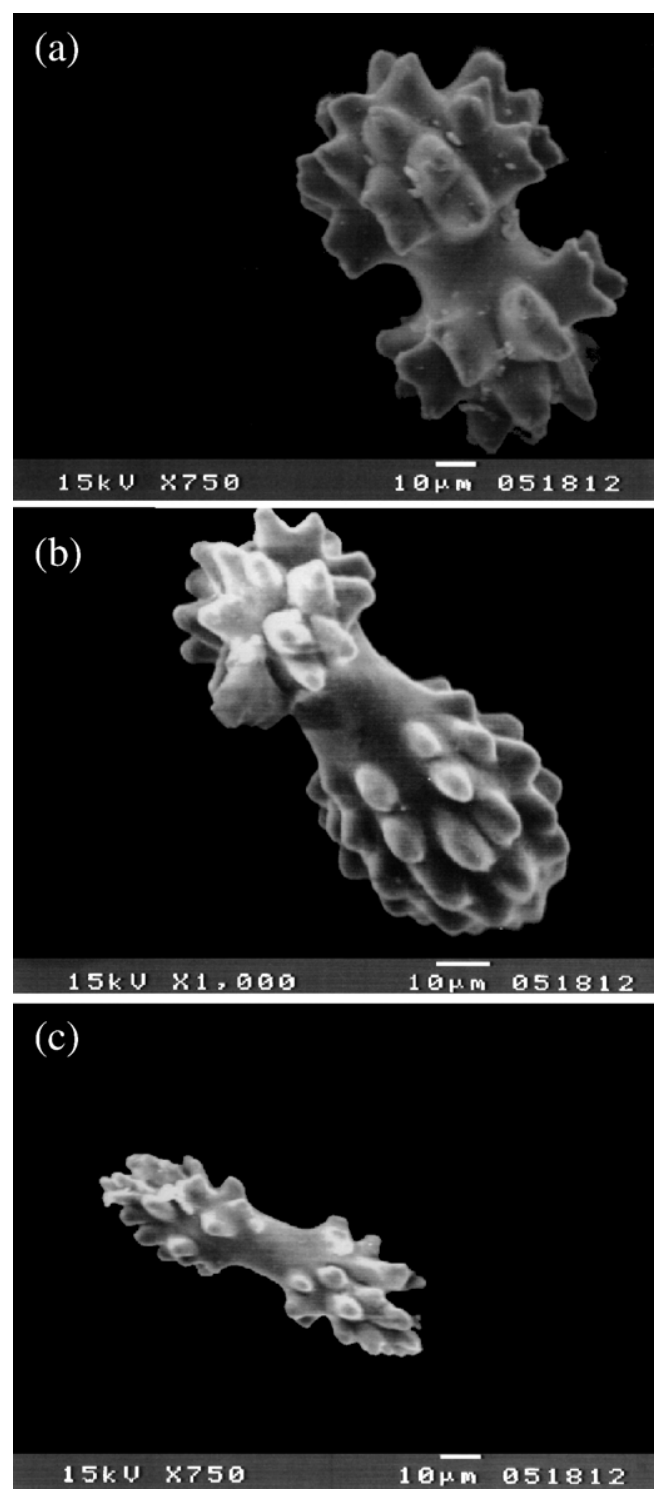

Fig. 2. Scanning micrographs of sclerites found in Junceella fragilis. Three major types are identified: double-head (a), club (b), and spindle (c).

was calculated based on the trapezoid rule for integration using the colony height $(h)$ and colony diameter $\left(d_{\mathrm{c}}\right)$ at its top, middle, and basal portions.

\subsection{Data analyses}

Allometric relationships between colony height and the morphological or weight data were described using a power function, $Y=a X^{b}$, in its log-transformed linear form:

$\log Y=\log a+b \log X$ 
where $Y$ is the particular parameter of interest, $X$ is the colony height, and $a$ and $b$ are empirically determined constants, with $b$ being the allometric exponent in the original form, and the slope or regression coefficient of the log-transformed linear relationship. To this end, data were first log-transformed followed by least-squares regression (LSR) analyses. To compare the regression lines either between two populations or among the three colony regions, analysis of covariance (ANCOVA) was performed using SAS. One-way analysis of variance (ANOVA) and Duncan's multiple range test were used to compare the frequencies of the three sclerite types. To compare the mechanical consequences of different growth patterns (modular, isometric, and our results), the allometric exponent b (i.e., the LSR slopes of the $\log -\log$ relationship) for several morphological and mechanical parameters in relation to colony height was derived from Eqs. (3), (4), and (6).

(a)



(c)

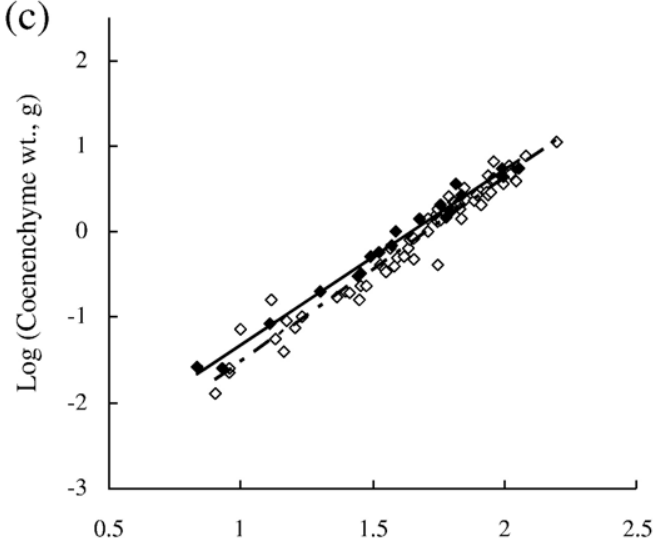

\section{Results}

\subsection{Colony size and its content variations}

In general, the weight of the four major components in a $J$. fragilis colony, namely the axial skeleton, sclerites, coenenchymal tissue, and water, increased with colony height in both populations (Fig. 3). The LSRs of the log-transformed data showed no significant difference between the slopes of the two populations (ANCOVA, $0.30<p<0.57$ for all cases). The slope for the axial skeleton weight was approximately 3 (Fig. 3a), while those for the other three components fell between 2.0 and 2.2 (Fig. 3b-d) $\left(r^{2}>0.96, p<0.01\right.$ for all cases). The adjusted means of the intercepts, however, significantly differed between the two populations (ANCOVA, $0.0005<p<0.03$ for all cases). Among the four components analyzed, the weight of axial skeleton


Log (Colony height, $\mathrm{cm}$ )

Fig. 3. Relationship between colony height and total weight (wt.) of four major components in each Junceella fragilis colony, including (a) the axial skeleton, (b) sclerites, (c) coenenchymal tissue, and (d) water, in the two studied populations. All data were log-transformed and fitted with leastsquare regressions. 
for the Leidashi population was about twice that for the Xiashuijui population. On the contrary, the Leidashi population had lower weights for the other three components.

The relative amounts of these four components, however, showed different patterns with colony height (Fig. 4). In both populations, fleshy tissue accounted for a constant proportion of the overall weight, while water slightly decreased across the range of colony size. The two types of skeletal support components showed different patterns with colony growth: the relative amount of the axial skeleton increased while that of sclerites decreased with colony height (Fig. 4). The LSR line had a negative slope for sclerites $(-0.18$ for Leidashi and -0.13 for Xiashuijui) and a positive slope for the axial skeleton ( 0.29 for Leidashi and 0.22 for Xiashuijui) $\left(r^{2}>0.77, p<0.01\right.$ for all cases). In both populations, the skeletal weight was dominated by sclerites in short colonies but reverted to axial skeleton in longer ones (Fig. 4). The intersection of regression lines for the rising axial skeleton and the declining sclerite support occurred at colony height of approximately $94 \mathrm{~cm}$ at Leidashi, and of $109 \mathrm{~cm}$ at Xiashuijui.

\subsection{Distribution of skeletal components within a colony}

The diameter of the axial skeleton was greatest at the colony base, followed by the middle and top portions for both populations (Fig. 5a, b). LSR lines of logtransformed data showed that the diameters at the base and middle portions increased with colony height (slope $>0.8, r^{2}>0.85$ for both populations), but the diameter at the colony top had a weak association with height $\left(r^{2}<0.1\right.$ for both populations). The Leidashi colonies had thicker axial skeletons that also increased at a greater rate with height (the slopes of the base and middle parts of Leidashi vs. Xiashuijui populations were 1.26 vs. 0.84 , and 0.88 vs. 0.79 , respectively; ANCOVA, $p<0.003$ ) (Fig. 5a, b). On the contrary, the coenenchymal thickness showed a different pattern: it was greatest in the middle of a colony, followed by the top and basal portions (Fig. 5c, d). In general, the coenenchymal thickness increased with colony height except at the base for the Leidashi colonies (slopes ca. $0.5-0.6$ for the middle and top portions of a colony, $r^{2}>0.8$ ).

For any portion of a colony, sclerite weight fraction accounted for similar (Xiashuijui population, Fig. 6b) or

(a)

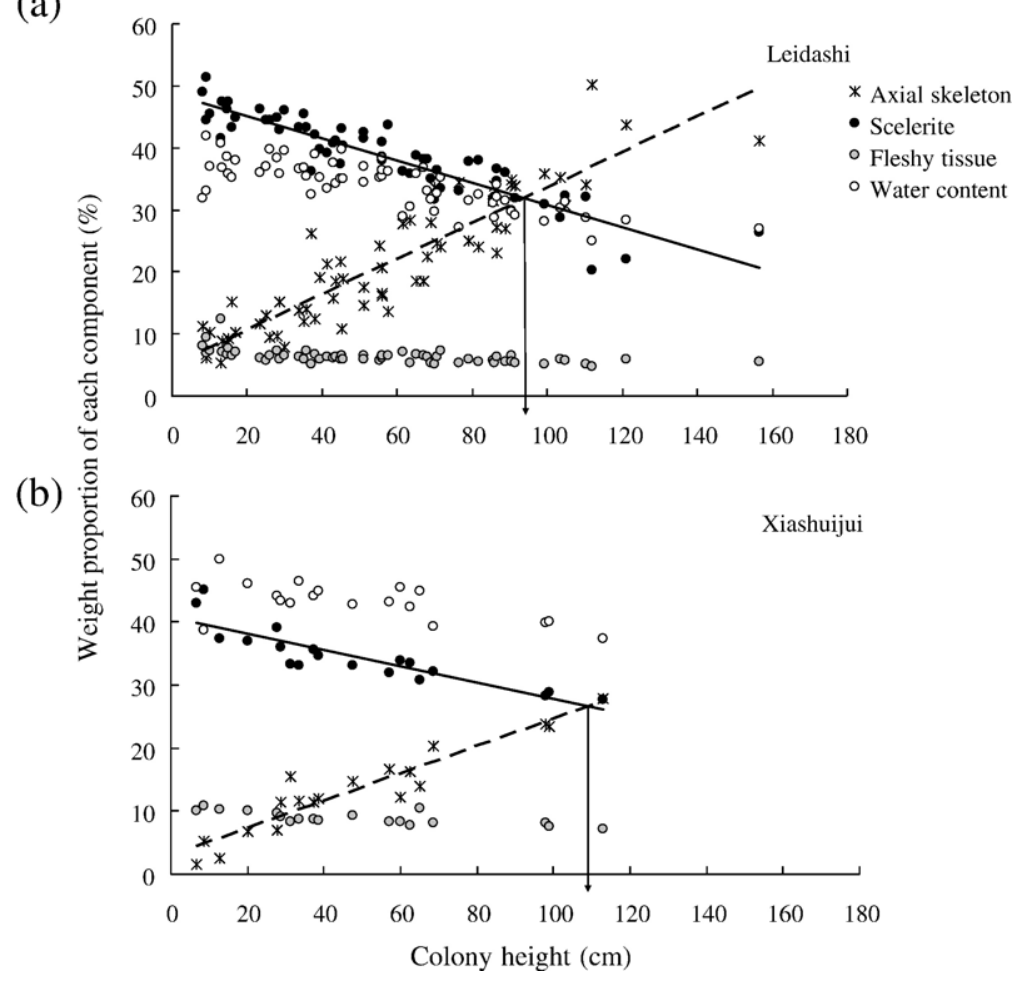

Fig. 4. Relationship between colony height and the relative amount of each component in the entire Junceella fragilis colony in two populations (a: Leidashi, and b: Xiashuijui). Regression lines are drawn for the axial skeleton (dashed lines) and sclerites (solid lines). The vertical arrows show the colony height at which the weight proportion of axial skeleton equals that of sclerites. 
(a)

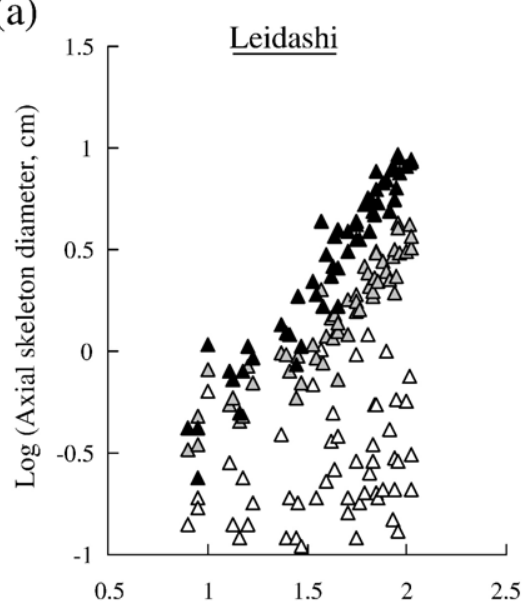

(c)



(b)

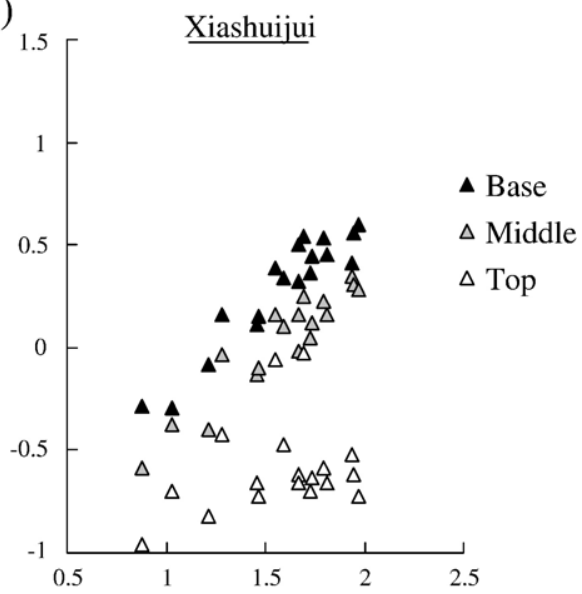

(d)



Log (Colony height, $\mathrm{cm})$

Fig. 5. Relationship between colony height and axial skeleton diameter (a, b) or coenenchymal thickness (c, d) in three regions (base, middle, and top) of Junceella fragilis colonies in the two studied populations. All data were log-transformed.

slightly decreased (Leidashi population, Fig. 6a) fractions of the dried coenenchymal weight across colony heights (LSR, $r^{2}>0.67, p<0.01$ ). Using pooled data for colonies of different heights, the coenenchyme at the colony base had more sclerites $(88.2 \pm 3.4 \%)$ than did the upper regions $(83.3 \% \pm 4.8 \%)$; ANOVA, $p<0.05)$ (Fig. 7).

Three major forms of sclerites were found in a $J$. fragilis colony: double-heads $(0.09 \pm 0.004 \mathrm{~mm}$ in length, $n=10)$, clubs $(0.08 \pm 0.006 \mathrm{~mm}, n=10)$, and spindles $(0.05 \pm 0.007 \mathrm{~mm}, n=8)$. Within a colony, the relative frequency of each sclerite type significantly differed between the colony base and its upper regions: double-heads dominated the colony base $(60.1 \% \pm$ $14.1 \%)$, followed by clubs $(39.2 \% \pm 13.7 \%)$; however, more clubs $(66.7 \% \pm 9.2 \%)$ were found in the upper colony regions than double-heads $(27.7 \% \pm 9.4 \%)$ (Fig. 7) (ANOVA, $p<0.05$ ). Although spindles were found in $J$. fragilis colonies, they were quite scarce $(0.8 \% \pm 1.1 \%$ and $5.7 \% \pm 3.8 \%$ for the basal and upper regions, respectively).

\subsection{Estimated maximum stress in the axial skeleton during bending}

Assuming a flow velocity of $1 \mathrm{~m} \mathrm{~s}^{-1}$, the bending moment showed similar relationships with colony height in both populations with a slope of 2.65 (Fig. 8a). $\sqrt{\frac{d_{a}^{3}}{d_{c}}}$ increased at a greater rate in the Leidashi colonies than in the Xiashuijui ones (with slopes of 1.55 vs. 0.93, respectively; ANCOVA, $p<0.0001$ ) (Fig. 8b). Consequently, the maximum stress remained fairly constant in 
(a)

(b)

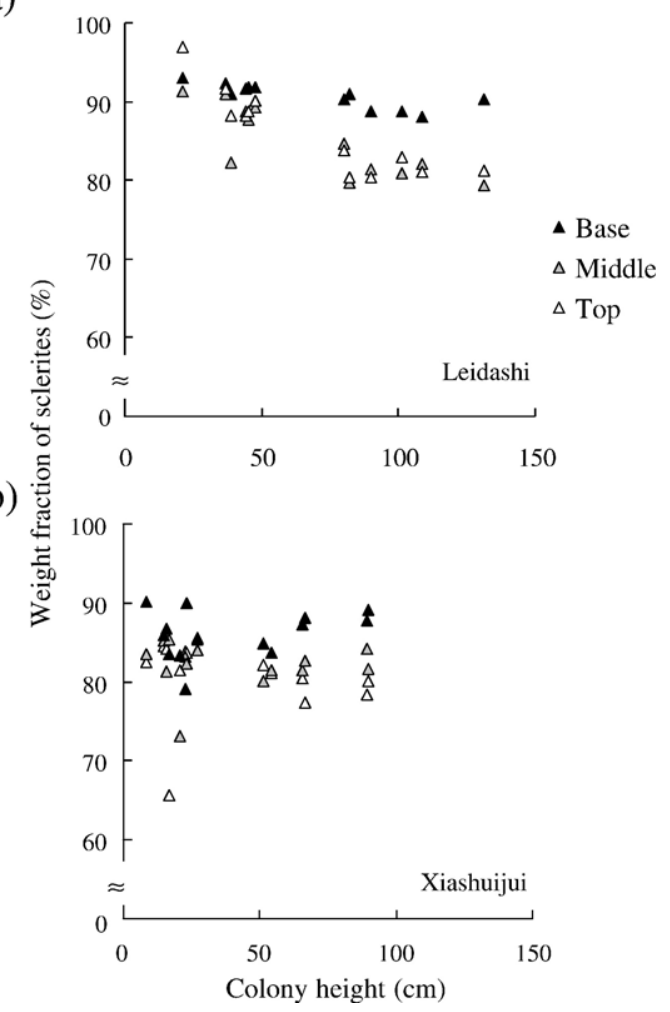

Fig. 6. Relationship between colony height and the weight fraction of sclerites to the dried coenenchyme at three regions (base, middle, and top) of Junceella fragilis colonies of the two studied populations (a: Leidashi, and b: Xiashuijui). the Xiashuijui population but slightly decreased in the Leidashi population across the range of colony heights (with slopes of 0.13 vs. -1.11 , respectively; ANCOVA, $p<0.0001)$. As a result, long colonies at Leidashi experienced significantly lower stresses (Fig. 8c). Table 1 summarizes the predicted values of allometric exponent $b$ for both the modular and isometric growth patterns, as well as our results from the two populations.

\section{Discussion}

When a $J$. fragilis colony grows, the bending moment caused by drag increases not only with its projected area, but also by the product of its area and height (Eq. (3)). Therefore, a sea whip colony growing only lengthwise (modular growth) will encounter greater bending stresses within its support system (Table 1). Our calculations using morphometric data revealed that neither population of $J$. fragilis grows in a modular pattern (Fig. 5). Even though the entire colony increases in diameter during growth, its axial skeleton grows disproportionately thicker presumably to compensate for the increased drag and bending moment (Fig. 5a, b; Table 1). In our hypothesis, we stated that a constant bending stress of the axial skeleton could be achieved if $\sqrt{\frac{d_{a}^{3}}{d_{c}}}$ is directly proportional to the colony height. An allometric exponent being close to or greater than one, as found in our study (Fig. 8b), suggests that the axial skeleton of $J$. fragilis does grow in a manner which maintains or even reduces the bending stress as a colony grows (Fig. 8c).

Our results suggest that sclerites may play an important role in supporting the coenenchyme of $J$.

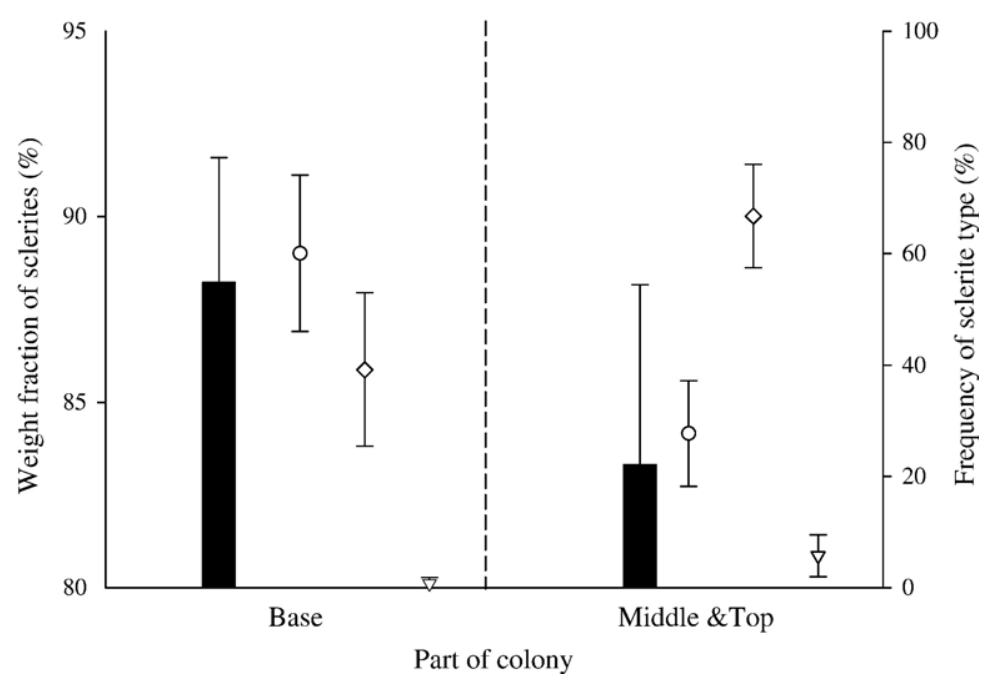

Fig. 7. Regional variations in the sclerite weight fraction (black bars, left axis) and the frequency of each type (right axis; ○: double-head, $\diamond:$ club, $\nabla$ : spindle). 
(a)

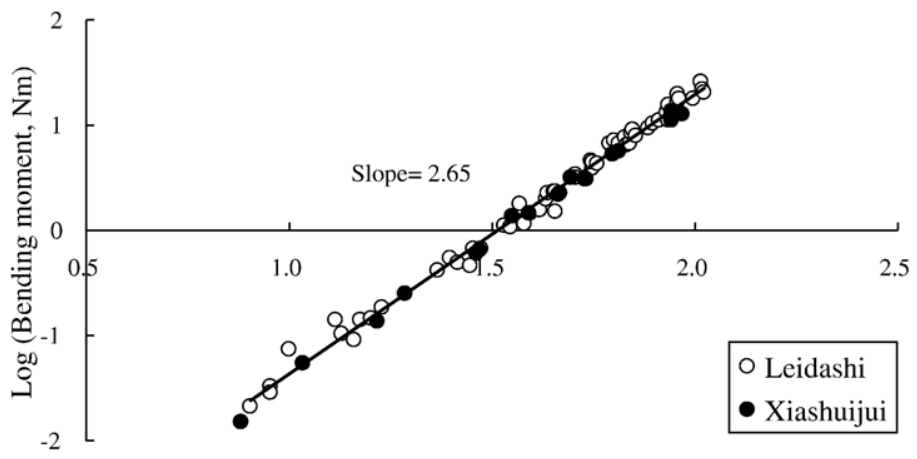

(b)

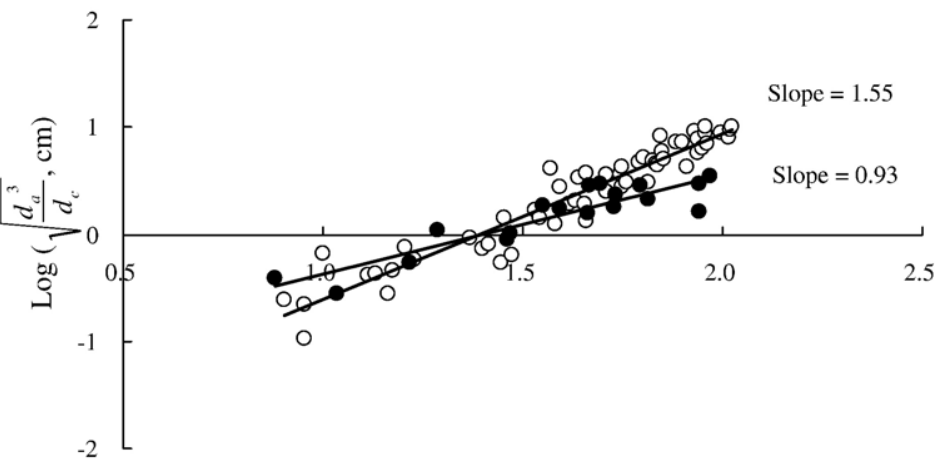

(c)



Fig. 8. Relationship between colony height and the bending moment, $\sqrt{\frac{d_{\mathrm{d}}^{3}}{d_{\mathrm{c}}}}$, and maximum bending stress at a flow velocity of $1 \mathrm{~m} / \mathrm{s}$ in the two studied Junceella fragilis populations.

fragilis. An allometric exponent close to two suggests that the total sclerite weight increases directly with the surface area, instead of the weight of the colony (Fig. $3 \mathrm{~b})$. A higher density of sclerites has been suggested to enhance the rigidity of some sponges and cnidarians (Koehl, 1982; Lewis and Von Wallis, 1991; West, 1998). More sclerites found in the coenenchyme at the colony base as opposed to the upper regions (Fig. 6) implies greater mechanical reinforcement to compen- sate for increased local stresses in a bending colony. On the other hand, a similar sclerite weight fraction agrees with similar stress calculations for the unbent upper regions (Fig. 6). Therefore, our results provide evidence that hydrodynamic forces are a determining factor affecting the distribution of sclerites in $J$. fragilis colonies. This complements the non-defensive role of sclerites suggested by Van Alstyne and Paul (1992). 
Table 1

Summary of the allometric exponent $b$ of several morphological and mechanical parameters, in relation to colony height, for predictions from modular and isometric growth patterns, as well as results in two southern Taiwan populations

\begin{tabular}{|c|c|c|c|c|c|c|}
\hline \multirow[t]{2}{*}{ Allometric exponent $b$} & \multicolumn{2}{|l|}{ Scaling } & \multicolumn{4}{|l|}{ Derivation } \\
\hline & $\begin{array}{l}\text { Axis diameter } \\
\left(\mathrm{d}_{\mathrm{a}}\right)\end{array}$ & $\begin{array}{l}\text { Colony diameter } \\
\left(\mathrm{d}_{\mathrm{c}}\right)\end{array}$ & $\begin{array}{l}\text { Projected colony } \\
\text { area }(\mathrm{S})\end{array}$ & $\begin{array}{l}\text { Bending moment } \\
(\mathrm{M})^{\mathrm{a}}\end{array}$ & $\begin{array}{l}\text { Second moment of } \\
\text { area of axial base }(\mathrm{I})^{\mathrm{b}}\end{array}$ & $\begin{array}{l}\text { Maximum stress } \\
\text { on axis }\left(\sigma_{\max }\right)^{\mathrm{c}}\end{array}$ \\
\hline \multicolumn{7}{|c|}{ Growth patterns: predictions } \\
\hline Modular & 0 & 0 & 1 & 2 & 0 & 2 \\
\hline Isometric & 1 & 1 & 2 & 3 & 4 & 0 \\
\hline \multicolumn{7}{|l|}{ Results } \\
\hline Leidashi & 1.26 & 0.67 & 1.67 & 2.67 & 5.04 & -1.11 \\
\hline Xiashuijui & 0.84 & 0.67 & 1.67 & 2.67 & 3.36 & 0.15 \\
\hline
\end{tabular}

${ }^{\mathrm{a}}$ Calculated from Eq. (3); ${ }^{\mathrm{b}}$ Calculated from Eq. (6); ${ }^{\mathrm{c}}$ Calculated from Eq. (4).

Variations in the typological distribution of sclerites within a $J$. fragilis colony may have a functional bearing. It has been suggested that double-heads can resist coenenchymal deformation both in extension and compression through their close packing and random orientation, whereas clubs mainly resist compression (Lewis and Von Wallis, 1991). Consequently, more double-heads at the colony base can protect the coenenchyme from excessive deformation due to bending. In contrast, the upper regions are less prone to bending and the reduced weight of clubs, as opposed to the double-heads of similar length, can also save materials and provide more protection for the feeding polyps (Lewis and Von Wallis, 1991).

The axial skeleton and sclerites may play different mechanical roles in the life history of $J$. fragilis. Skeletal support is accomplished almost exclusively by sclerites in short colonies, but this function is gradually taken over by the axial skeleton during growth (Fig. 4). It has been proposed that sclerites stiffen the collagenous matrix, hence providing mechanical support for soft corals and some gorgonians without an axial skeleton (Koehl, 1982; Lin and Dai, 1997). The significantly greater weight of sclerites compared to the axial skeleton found in small colonies implies that the sclerites can provide colony support for gorgonian corals with an axial skeleton. The advantage of having more sclerites at a small size might be because the sclerites are more cost-effective, since the formation of sclerites is metabolically cheaper than that of gorgonin. Unlike soft corals that deform easily and have a low height-to-width ratio, sea whips and branching gorgonian corals experience greater bending stresses in longer colonies and therefore require stronger skeletal material than sclerite-reinforced tissue (Jeyasuria and Lewis, 1987; Lewis et al., 1992). The flexibility and the elasticity granted by the gorgonin axial skeleton may also allow the colony to withstand stronger hydrodynamic forces by bending, and to return to an upright position once the external load is removed (Wainwright et al., 1976).

$J$. fragilis colonies exhibit different skeletal arrangements in different flow environments. Although the average colony diameter, and hence the drag and bending moment increased at similar rates for the two populations (Fig. 8a; Table 1), the axial skeletal diameter at the colony base increased at a greater rate in the Leidashi population than the Xiashuijui one (Fig. 5a, b; Table 1). Consequently, the skeleton of Leidashi colonies would have decreased bending stresses in longer colonies (Fig. 8c; Table 1). It is generally believed that the support systems of organisms undergo mechanical adaptations to their environment (Wainwright et al., 1976). It is possible that the Leidashi colonies have incorporated more skeletal materials, both the gorgonin axis and sclerites, to survive in a more-challenging environment. Furthermore, coral colonies inhabiting an environment with stronger water flow (such as Leidashi) may switch to using stronger materials, such as gorgonin, as the dominant skeletal support in an earlier stage than would those in an environment with weaker ambient flows (Fig. 4).

Although this study only focused on $J$. fragilis, we believe that during growth, other sessile marine organisms face similar mechanical challenges and may apply similar mechanisms to deal with increasing hydrodynamic forces, that is, by increasing strength and flexibility of their skeletal supports. Such trend has been reported in other gorgonian corals with differing skeletal compositions at the species and population levels, but no data are available during their growth (Muzik and Wainwright, 1977; Jeyasuria and Lewis, 1987; West et al., 1993). However, the giant blue kelps Nereocystis luetkeana are found to modify their stipe properties to maintain a constant tensile stress during ontogeny and in different flow environments (Koehl, 1999). 
In conclusion, sea whip (J. fragilis) colonies modify their skeletal supports to compensate for the mechanical consequences of growth. During growth, a stronger gorgonin axial skeleton overtakes sclerites as the main support and increases in a way to maintain or even slightly decrease the bending stresses at the colony base. Sclerites, on the other hand, serve as a complementary support in larger colonies, and play more important roles in supporting the feeding polyps and maintaining the integrity of the coenenchyme. Furthermore, colonies inhabiting stronger-flow environments incorporate more skeletal materials. This study demonstrates how sessile marine organisms cope with mechanical challenges during their life history by modifying their constitution and construction of their support systems.

\section{Acknowledgements}

We would like to thank Yu-xiang Chou and Shang-yin Vanson Liu for their assistance with field work, Dr. Min-li Tsai for his help with statistical analyses and Dr. Zohar Pasternak for his helpful comments on an earlier draft of this manuscript. This research was funded by the National Science Council of the Republic of China (NSC 94-2611M-002-010 and 94-2811-M-002-098). [RH]

\section{Appendix A. Derivation of the maximum bending stress}

From Eq. (2), the maximum bending stress, $\sigma_{\max }$, at the colony base can be calculated as:

$\sigma_{\max }=\frac{M d_{\mathrm{a}}}{2 I}$

where $I$ is the second moment of area and can be calculated by the following formula for a circular crosssection:

$I=\frac{\pi r^{4}}{4}=\frac{\pi d_{\mathrm{a}}^{4}}{64}$.

Assume in the absence of a velocity gradient that the bending moment, $M$, at the base of the colony is the product of the drag force $(D)$ and the average moment arm (i.e., half the colony height, $h / 2$ ). Therefore, substituting $D$ by Eq. (1) we get

$$
\begin{aligned}
M & =D \cdot\left(\frac{1}{2} h\right)=\frac{1}{2} C_{\mathrm{d}} \rho S v^{2} \cdot \frac{1}{2} h \\
& =\frac{1}{4} C_{\mathrm{d}} \rho \cdot(h \cdot S) \cdot v^{2} .
\end{aligned}
$$

The projected surface area of the colony $(S)$, assuming a cylindrical shape, is the product of the colony height $(h)$ and colony diameter $\left(d_{\mathrm{c}}\right)$. Substituting Eqs. (3) and (6) into Eq. (2), we can calculate the maximum stress as:

$$
\begin{aligned}
\sigma_{\max } & =\frac{M d_{\mathrm{a}}}{2 I}=\frac{\frac{1}{4} C_{\mathrm{d}} \rho(h S) v^{2} d_{\mathrm{a}}}{2 \frac{\pi d_{\mathrm{a}}^{4}}{64}} \\
& =\frac{8 C_{\mathrm{d}} \rho}{\pi} \cdot\left(\frac{h^{2} d_{\mathrm{c}}}{d_{\mathrm{a}}^{3}}\right) \cdot v^{2} .
\end{aligned}
$$

\section{References}

Boller, M.L., Swain, T.D., Lasker, H.R., 2002. Skeletal morphology and material properties of a fragmenting gorgonian coral. Mar. Ecol. Prog. Ser. 228, 131-141.

Chen, C.C., Chang, K.H., 1991. Gorgonacea (Coelenterata: Anthozoa: Octocorallia) of southern Taiwan. Bull. Inst. Zool. Acad. Sin. 30, 49-182.

Denny, M.W., 1988. Biology and the Mechanical of the Wave-swept Environment. Princeton University Press, Princeton.

Denny, M., 1999. Are there mechanical limits to size in wave-swept organisms? J. Exp. Biol. 202, 3463-3467.

Denny, M., Gaylord, B., 2002. The mechanics of wave-swept algae. J. Exp. Biol. 205, 1355-1362.

Esford, L.E., Lewis, J.C., 1990. Stiffness of Caribbean gorgonians (Coelenterata, Octocorallia) and $\mathrm{Ca} / \mathrm{Mg}$ content of their axes. Mar. Ecol. Prog. Ser. 67, 189-200.

Fabricius, K., Alderslade, P., 2001. Soft Corals and Sea Fans: A comprehensive guide to the tropical shallow-water genera of the Central-West Pacific, the Indian Ocean and the Red Sea. Australian Institute of Marine Science, Queensland, Australia.

Goldberg, W.M., 1976. Comparative study of the chemistry and structure of gorgonian and Antipatharian coral skeleton. Mar. Biol. $35,253-267$.

Grigg, R.W., 1972. Orientation and growth form of sea fans. Limnol. Oceanogr. 34, 382-389.

Grillo, M.-C., Goldberg, W.M., Allemand, D., 1993. Skeleton and sclerite formation in the precious red coral Corallium rubrum. Mar. Biol. 117, 119-128.

Harvell, C.D., Fenical, W., 1989. Chemical and structural defenses of Caribbean gorgonians (Pseudopterogogia spp.): intracolony localization of defense. Limnol. Oceanogr. 34, 382-389.

Harvell, C.D., Suchanek, T.S., 1987. Partial predation on tropical gorgonians by Cyphoma gibbosum (Gastropoda). Mar. Ecol. Prog. Ser. 38, 37-44.

Harvell, C.D., Fenical, W., Greene, C.H., 1988. Chemical and structural defenses of Caribbean gorgonians (Pseudopterogorgia spp.): development of an in situ feeding assay. Mar. Ecol. Prog. Ser. 49, 287-294.

Jeyasuria, P., Lewis, J.C., 1987. Mechanical properties of the axial skeleton in gorgonians. Coral Reefs 5, 213-219.

Jokiel, P., 1978. Effects of water movement on reef corals. J. Exp. Mar. Biol. Ecol. 35, 87-97.

Kim, A., Close, L., DeWreede, R.E., Lynch, B.J., Ormond, C., Walker, M., 2006. Biomechanical properties and holdfast morphology of coenocytic algae (Halimedales, Chlorophyta) in Bocas del Toro, Panama. J. Exp. Mar. Biol. Ecol. 328, 155-167.

Koehl, M.A.R., 1982. Mechanical design of spicule-reinforced connective tissues: stiffness. J. Exp. Biol. 98, 239-268.

Koehl, M., 1984. How do benthic organisms withstand moving water? Am. Zool. 24, 57-70. 
Koehl, M.A.R., 1999. Ecological biomechanics of benthic organisms: life history, mechanical design and temporal patterns of mechanical stress. J. Exp. Biol. 202, 3469-3476.

Lee, H.J., Chao, S.Y., Fan, K.L., 1999. Flood-ebb disparity of tidally induced recirculation eddies in a semi-enclosed basin: Nan Wan Bay. Cont. Shelf Res. 19, 871-890.

Lewis, J.C., Von Wallis, E., 1991. The function of surface sclerites in gorgonians (Coelenterata, Octocorallia). Biol. Bull. 181, 275-288.

Lewis, J.C., Barnowski, T.F., Telesnicki, G.J., 1992. Characteristic of carbonates of gorgonian axes (Coelenterata, Octocorallia). Biol. Bull. 183, 278-296.

Lin, M.C., Dai, C.F., 1996. Drag, morphology and mechanical properties of three species of octocorals. J Exp. Mar. Biol. Ecol. 201, 13-22.

Lin, M.C., Dai, C.F., 1997. Morphology and mechanical properties of two alcyonaceans, Sinularia flexibilis and S. capillosa. Zool. Stud. $36,58-63$.

Muzik, K., Wainwright, S.A., 1977. Morphology and habitat of five Fijian sea fans. Bull. Mar. Sci. 27, 308-377.

Shashar, N., Kinane, S., Jokiel, P.L., Patterson, M.R., 1996. Hydromechanical boundary layers over a coral reef. J. Exp. Mar. Biol. Ecol. 199, 17-28.

Van Alstyne, K.L., Paul, V.J., 1992. Antipredator defenses in tropical pacific soft corals (Coelenterata: Alcyonacea). I. sclerites as defenses against generallist carnivorous fish. Biol. Bull. 182, 231-240.

Vermeire, J.M., 1994. Reproduction and growth of a gorgonian sea whip, Junceella fragilis, in Southern Taiwan. MS thesis, Institute of Oceanography. National Taiwan University, Taipei.
Vogel, S., 1994. Life in Moving Fluids. Princeton University Press, Princeton, NJ.

Vogel, S., 2003. Comparative Biomechanics: Life's Physical World. Princeton University Press, Princeton, NJ.

Wainwright, S.A., Dillon, J.R., 1969. On the orientation of sea fans (Genus Gorgonia). Biol. Bull. 136, 130-139.

Wainwright, S.A., Biggs, W.D., Curry, J.D., Gosline, J.M., 1976. Mechanical Design in Organisms. Princeton University Press, Princeton, NJ.

Walker, T.A., Bull, G.D., 1983. A newly discovered method of reproduction in gorgonian coral. Mar. Ecol. Prog. Ser. 12, 137-143.

West, J.M., 1996. Skeletal variation in the Caribbean coral Briareum asbestinum (Gorgonacea): pattern and process across enviromental gradients. Cornell University, Ithaca, NY.

West, J.M., 1997. Plasticity in the sclerites of a gorgonian coral: tests of water motion, light level, and damage cues. Biol. Bull. 192, 279-289.

West, J.M., 1998. The dual role of sclerites in a gorgonian coral: conflicting functions of support and defence. Evol. Ecol. 12, $803-821$.

West, J.M., Harvell, C.D., Walls, A.M., 1993. Morphological plasticity in a gorgonian coral (Briareum asbestinum) over a depth cline. Mar. Ecol. Prog. Ser. 96, 61-69. 